\title{
Genome
}

\section{Insights on mauritiana-like Elements Diversity in Mayetiola destructor and M. hordei (Diptera: Cecidomyiidae)}

\begin{tabular}{|c|c|}
\hline Journal: & Genome \\
\hline Manuscript ID & gen-2021-0020.R3 \\
\hline Manuscript Type: & Article \\
\hline $\begin{array}{r}\text { Date Submitted by the } \\
\text { Author: }\end{array}$ & $06-N o v-2021$ \\
\hline Complete List of Authors: & $\begin{array}{l}\text { Ben Amara, Wiem; University of Tunis El Manar Faculty of Sciences of } \\
\text { Tunis, Laboratory of Biochemistry and Biotechnology (LR01ES05) } \\
\text { Djebbi, Salma; University of Tunis El Manar Faculty of Sciences of Tunis, } \\
\text { Laboratory of Biochemistry and Biotechnology (LR01ES05) } \\
\text { Ben Lazhar-Ajroud, Wafa; University of Tunis El Manar Faculty of } \\
\text { Sciences of Tunis, Laboratory of Biochemistry and Biotechnology } \\
\text { (LR01ES05) } \\
\text { Naccache, Chahnez; University of Tunis El Manar } \\
\text { Mezghani, Maha; University of Tunis El Manar Faculty of Sciences of } \\
\text { Tunis, Laboratory of Biochemistry and Biotechnology (LR01ES05) }\end{array}$ \\
\hline Keyword: & $\begin{array}{l}\text { Mayetiola destructor, Mayetiola hordei, transposable elements, MLEs, } \\
\text { Diversity }\end{array}$ \\
\hline $\begin{array}{r}\text { Is the invited manuscript for } \\
\text { consideration in a Special } \\
\text { Issue? : }\end{array}$ & Not applicable (regular submission) \\
\hline
\end{tabular}

\section{SCHOLARONE" \\ Manuscripts}


2 Insights on mauritiana-like Elements Diversity in Mayetiola destructor and M.

$3 \quad$ hordei (Diptera: Cecidomyiidae)

4

5 Wiem Ben Amara ${ }^{1,2}$, Salma Djebbi ${ }^{1}$, Wafa Ben Lazhar-Ajroud ${ }^{1}$, Chahnez Naccache ${ }^{1}$ and Maha

6 Mezghani-Khemakhem ${ }^{1 *}$

$7 \quad{ }^{1}$ Laboratory of Biochemistry and Biotechnology (LR01ES05), Faculty of Sciences of Tunis, University of Tunis

8 El Manar, Tunisia

9

10

${ }^{2}$ Sciences Department, CANOPUS International School of Tunis, Tunisia (CIST) 
Abstract:

Mariner-like elements (MLEs) are class II transposons belonging to the Tc1-mariner family, that have successfully invaded many insect genomes. In the current study, the availability of the Hessian fly Mayetiola destructor genome has enabled us to perform in silico analysis of MLEs using as query the previously described mariner element (Desmarl) belonging to mauritiana subfamily. Eighteen mauritiana-like elements were detected and were clustered into three main groups named Desmarl-like, MauCons1 and MauCons2. Subsequently, in vitro analysis was carried out to investigate mauritiana-like elements in $M$. destructor as well as in Mayetiola hordei using primers designed from TIRs of the previously identified MLEs. PCR amplifications were successful and a total of 12 and 17 mauritiana-like elements were discovered in $M$. destructor and $M$. hordei, respectively. Sequence analyses of mauritiana-like elements obtained in silico and in vitro have showed that MauCons 1 and MauCons 2 elements share low similarity with Desmarl ranging from $50 \%$ to $55 \%$ suggesting different groups under mauritiana subfamily have invaded the genomes of $M$. destructor and $M$. hordei. These groups are likely inherited by vertical transmission that subsequently underwent different evolutionary histories. This work describes new mauritiana-like elements in M. destructor that are distinct from the previouslydiscovered Desmarl and provides the first evidence of MLEs belonging to mauritiana subfamily in M. hordei.

Keywords: Mayetiola destructor, Mayetiola hordei, transposable elements, MLEs, mauritiana, diversity

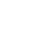


52

Transposable elements (TEs) are repetitive DNA sequences able to move from one chromosome to another within the host genome (Mackay, 1989). They are present in the genome of most living organisms with a large range of proportions varying from $1 \%$ in prokaryotic genomes to $90 \%$ in some plant genomes (Touchon and Rocha, 2007, Guio and Gonzalez, 2019). TEs activity leads to the generation of various mutations and chromosomal rearrangements including insertions, deletions, inversions, duplications, and translocations. These mutations can be deleterious to the host organism but can also be beneficial by providing new advantageous host functions through domestication or gene regulation. (Kidwell and Lisch, 1997, Chenais et al., 2012, Bourgeois and Boissinot, 2019, Klai et al., 2020).

TEs are classified according to their transposition intermediates into Class I elements or retrotransposons which transpose through "Copy-Paste" mechanism and Class II elements or DNA transposons that use the "Cut and Paste" mechanism for transposition (Wicker et al., 2007, Kapitonov and Jurka, 2008). Additionally, TEs can be autonomous, able to move independently using their own transposition enzymes, or non-autonomous elements, which require the enzymatic machinery of autonomous elements to be mobilized (Feschotte and Pritham, 2007).

The Tc1/mariner transposons are the most widespread superfamily of DNA transposons among eukaryotes (Yuan and Wessler, 2011). TEs of Tc1/mariner superfamily are classified into at least eight families according to the DDE/D signature variants, namely: DD34E/Tc1-Like Elements (TLEs) (Emmons et al., 1983), DD34D/Mariner-Like Elements (MLEs) (Jacobson et al., 1986), DD35E/TR (Zong et al., 2020), DD36E/IC (Sang et al., 2019), DD37D/ maT (Zhang et al., 2016), DD37E/TRT (Zhang et al. 2016), DD41D (Gomulski et al., 2001) and DDxD/pogo (Shao and Tu, 2001, Dupeyron et al., 2020, Wang et al., 2021). Among these various families of the Tc1/mariner superfamily, MLEs have been well studied in several eukaryotic organisms 
especially insects where they were identified for the first time (Jacobson et al., 1986, Robertson, 1993).

A full length $M L E$ exhibit a simple structure of approximately $1300 \mathrm{bp}$ in length consisting of an intronless gene encoding a transposase flanked by two terminal inverted repeats (TIRs) of 28-30 bp with typical TA dinucleotides serving as target site duplication (TSD).The MLE transposase is characterized by a N-terminal DNA-binding domain of Helix-Turn-Helix (HTH) type and a C-terminal catalytic domain with the conserved motif DD(34)D (Plasterk et al., 1999, Brillet et al., 2007, Yuan and Wessler, 2011).

At least eleven $M L E$ subfamilies have been described according to the similarities of the transposase catalytic core amino acid sequences (Robertson, 1997, Green and Frommer, 2001, Carr, 2008, Bui et al., 2007, Wallau et al., 2014, Zhang et al., 2015). However, five subfamilies are considered as the main references namely: cecropia, elegans/briggsae, irritans, mauritiana, mellifera (Robertson and MacLeod, 1993).

As all TEs, the $M L E s$ have a life cycle of three fundamental stages including invasion, maturity, and senescence (Kidwell and Lisch, 2001, Plasterk and van Luenen, 2002). The invasion stage consisting on the introduction of a TE into a virgin genome either by horizontal transfer (HT) mediated by introgression or vectors (Finnegan, 1985, Daniels et al., 1990).

During the maturity stage, the host genome will develop different mechanisms to reduce the $M L E$ activities and limit its deleterious proliferation. Mechanisms include Over Production Inhibition (OPI) (Lohe and Hartl, 1996) as well as epigenetic regulation by methylation and post-transcriptional regulation through piwiRNA (piRNA) or microRNA (miRNA), considered as candidates for silencing mechanisms (Hamilton et al., 2002, Xie et al., 2004, Abrusán and Krambeck, 2006, Piriyapongsa and Jordan, 2007).

During the senescence stage, a great loss of $M L E$ copies will happen and some of them could be extinct by vertical inactivation or stochastic loss (Le Rouzic and Capy, 2005, Lohe et al., 1995). To escape this selective pressure, some MLEs tend to invade new genomes by HT to 
102

103

104

105

106

107

108

109

110

111

112

113

114

115

116

117

initiate a new cycle and perpetuate. Horizontal transfer of MLEs was proposed for the first time in insects then it was reported in different taxa (Lampe et al., 2003, Robertson et al., 2002, Oliveira et al., 2012, Robertson and Lampe, 1995).

The Cecidomyiidae are one of the largest families of Diptera affecting cereals in different parts of the world. The Hessian fly, Mayetiola destructor (Say, 1817) and the barley gall midge, Mayetiola hordei (Kieffer, 1909) cause considerable damage to wheat and barley cultures particularly in the Mediterranean region, in Europe and in different states of USA (Gagné et al., 1991, Ratcliffe et al., 2000, Cherif et al., 2020, El Bouhssini et al., 2013). For more than half a century, $M$. destructor has been considered as an ideal model to study the plant-insect gene interactions (Harris et al., 2003, Stuart et al., 2012, Hatchett and Gallun, 1970, Flor, 1971).

The first described MLEs in M. destructor, were identified using a PCR-based method and consisted of partial elements belonging to irritans subfamily (Russell \& Shukle, 1995). Subsequently, a full-length copy of $M L E$ with intact ORF and perfect TIRs belonging to mauritiana subfamily were identified experimentally and named Desmarl (Russell and Shukle, 1997, Behura et al., 2010). More recently, irritans MLEs from TIR to TIR were identified in M. destructor and M. hordei using complementary approaches combining in silico analyses and in vitro experiments (Ben Amara et al., 2017). In M. hordei, MLEs of mauritiana elements have not yet been reported. In this work, we explore the diversity of mauritiana MLEs in both species of Mayetiola using experimental and homology-based methods.

\section{Materials and Methods}

\section{Insect Sampling and Identification}

Total DNA was extracted from individual insects of $M$. destructor and $M$. hordei using the salting-out protocol (Sunnucks and Hales, 1996) then conserved at $-20^{\circ} \mathrm{C}$ in sterile water. Species identification was carried out by PCR-RFLP of the cytochrome $b$ gene method described by Mezghani Khemakhem et al. (2002). 


\section{Data sources}

The M. destructor genome of $153 \mathrm{Mb}$ available in NCBI BioProject PRJNA45867 was used to identify MLEs mauritiana-like elements. This genome was assembled into 36,371 contigs with a $14 \mathrm{~kb}$ contig N50 length and 24,475 scaffolds with a $756 \mathrm{~kb}$ N50 length. In addition, the transcriptome shotgun assembly (TSA) of the orange wheat blossom midge Sitodiplosis mosellana (Diptera: Cecidomyiidae) was screened to identify similar mauritiana-like elements. This TSA consists of 24,383 complementary DNA (cDNA) contigs and is available in GenBank (PRJNA192921).

\section{In silico investigation of mauritiana-like elements}

The M. destructor whole genome sequence (WGS) was investigated to identify and characterize the MLEs of mauritiana subfamily. For this purpose, the Basic Local Alignment Search Tool:BLAST (Altschul et al., 1990) was applied with the default parameters using the whole Desmar1 element (from TIR to TIR) as a query (Accession number: U24436.1) to search and extract nucleotide sequences using the BLAST-N program. Genomic scaffolds exhibiting similarities with queries (E-value $<$ E-10) were selected and complete mauritiana-like elements were extracted.

\section{PCR amplifications}

A series of PCR has been performed to amplify mauritiana-like elements in M. destructor and M. hordei using primers listed in Table 1. These primers were designed from TIRs ends and from conserved domains of internal regions of $M L E s$. PCR program consisted of an initial cycle at $94^{\circ} \mathrm{C}$ for $4 \mathrm{~min}$ followed by 35 cycles of denaturation at $94^{\circ} \mathrm{C}$ for $15 \mathrm{~s}$, annealing step at varying temperatures depending on the sequences of the primers used and extension at $72^{\circ} \mathrm{C}$ for $2 \mathrm{~min}$ and a final extension at $72^{\circ} \mathrm{C}$ for $10 \mathrm{~min}$. PCR amplification products were visualized on $1 \%$ agarose gel stained with ethidium bromide then cloned and sequenced as described by Ben Amara et al. (2017) . 


\section{Inverse and nested PCR amplifications}

153

154

155

156

157

158

159

160

161

162

163

164

165

166

167

168

169

170

171

172

173

174

175

176

Genomic DNA (500 ng) were individually extracted from M. destructor and M. hordei and digested with $5 \mathrm{U}$ of restriction endonuclease EcoRI or DraI or HindIII (Promega ${ }^{\circledR}$ ) at $37^{\circ} \mathrm{C}$ for 1h then circularized in $150 \mu \mathrm{l}$ volume reaction containing $100 \mathrm{U}$ of T4 DNA Ligase (New England BioLabs) and $30 \mu 1$ of reaction buffer. After incubation for 5 hours at $37^{\circ} \mathrm{C}$, a volume of $10 \mu \mathrm{l}$ of circularized products is used to perform iPCR and nPCR using primers reported in Table 1 and conditions described by (Ben Lazhar-Ajroud et al., 2016). The products of iPCR and nPCR were subsequently purified, cloned and sequenced on both strands following the experimental protocol of Kharrat et al. (2015).

\section{Sequences and Phylogenetic analyses}

. TIRs were checked out using the online tool einverted (Durbin and Rice, 1999) and then aligned and visualized by CLC Genomics Workbench 9.5.3 program (https://www.qiagenbioinformatics.com/).

Alignment of the nucleotide and protein sequences of MLEs was performed by MAFFT program using the default parameters (gop 1.53; gep 0.123) then visualized on Genedoc (Nicholas and Nicholas, 1997, Long et al., 2016). The HTH domains of the transposases were predicted on the PRABI platform (Combet et al., 2000) and the NLS were predefined by the online program SeqNLS (Lin and Hu, 2013) using the transposase reference patterns described by Augé-Gouillou et al. (2001).

Phylogenetic relationships were established between MLEs of the two Mayetiola species and the $S$. mosellana as well as other mariner subgroups belonging to other insect species retrieved from GenBank and arbitrarily chosen. They were constructed by the Maximum Likelihood method according to the HKY85 model (Hasegawa et al., 1985) which was arbitrarily chosenwith a bootstrap of 1000 replication. Trees were obtained by Mega10 software (Kumar et al., 2018) then visualized and edited by the iTOL v3 program (Letunic and Bork, 2016). 
177

178

179

180

181

182

183

184

185

186

187

188

189

190

191

192

193

194

The classification of MLE sequences from M. destructor, M. hordei and S. mosellana was carried out using the Unweighted Pair Group Method with Variation of Metric (UPGM-VM) ) which is an ascending hierarchical classification analogous to the classical UPGMA with some methodological differences (Rouault et al., 2009, Filee et al., 2015). The classification was implemented among a set of 449 transposable elements belonging to the Tc1/mariner superfamily.

\section{Results}

\section{In silico identification of mauritiana-like elements in $M$. destructor genome}

The BLASTN using Desmarl as query allowed the identification of 17 contigs containing 18 sequences named Mdes1 to Mdes18. These elements were sized from 1202 to $1321 \mathrm{bp}$ and exhibited TIRs of 22 to 45 bp with the TA target site duplication (Table 2). Apart from Mdes 1 element, all identified MLEs have one or two imperfect TIRs flanking ORFs with stop, frameshift and/or indel mutations that encode putative transposases sizing from 324 to 368 aa. The phylogram inferred from the alignment of the 18 mauritiana-like elements with Desmarl and the other references of MLEs sub-families showed two clades; the first one included Desmarl and the 13 mauritiana-like elements (Mdes 1 to Mdes 13) while the second contained the 5 remaining mauritiana-like elements that are subdivided into two groups (Mdes15 to Mdes 18) and (Mdes 14) (Figure 1).

\section{In vitro search for mauritiana-like elements}

The mauritiana-like elements were amplified in M. destructor and M. hordei samples using the three primers DES, MauCons1, MauCons 2 designed from TIRs of Desmar1, Mdes15-Mdes 18 and Mdes 14, respectively (Figure 1). The resulted PCRs generated bands sized between 1100 and $1300 \mathrm{bp}$ corresponding to the typical sizes of MLEs in both species (Figure 2).

\section{- Characterization of Desmar1-like elements amplified by DES primer}


201

202

203

204

205

206

207

The Desmarl-like elements amplified by DES primer in $M$. destructor and M. hordei were designed according to the nomenclature proposed by Robertson and Asplund (1996). A total of five elements were identified in $M$. destructor and seven elements in $M$. hordei named Mdesmar1.1 to Mdesmar1.5 and Mhormar1.1 to Mhormar1.7, respectively. These elements are available under the GenBank accession numbers MW093693 to MW093697 and MW093705 to MW093711. Nucleotide sequence analyses showed a strong similarity between the Desmar 1like elements amplified in the two species ranging from $98 \%$ up to $100 \%$.

Like Desmarl, all predicted protein sequences exhibited a 347 aa transposase bordered by the MEN motif at the start and the YF/LE motif at the end except for Mdesmar1.4 which has a transposase of 330 aa (Figure 3a).

Transposase analyses showed that the two signature motifs WVPHEL and YSPDLAP were conserved except for Mdesmar1.5 which presents a substitution changing the Tryptophan (W) residue into Glycine $(\mathrm{G})$ in the first motif (Figure 3a). In addition, domains of the DD(34)D catalytic triad are maintained intact in all MLEs except for the element Mdemar1.4 which has a deletion of 17 amino acid in the C-terminal domain. This deletion extends from residue 146 to residue 162 covering the TGDEKW motif of the catalytic triad.

Further analyses revealed a TGA stop codon at position 200 in the Mdesmar1.1 element due to a transition from $\mathrm{G}$ to $\mathrm{A}$ of nucleotide 764 . Meanwhile, the four elements Mhormar1.1 to Mhormar1.4 showed a stop codon at position 173 due to a transversion from $\mathrm{T}$ to $\mathrm{A}$ of nucleotide 686.

In both species of Mayetiola, MLEs have TIRs displaying mirror and palindrome motifs centred around positions 14 and 15. TIRs are perfect in $M$. destructor and imperfect in $M$. hordei containing four substitutions at the positions 17, 18, 23 and 24 at the $5^{\prime}$ TIRs and only 2 substitutions at positions 23 and 27 at the 3' TIRs (Figure 3b). 
225

Noticeably, all the TIRs contain the conserved sequence 5'YYAGRT3' involved in the cleavage of the TIRs ends described by Bigot et al. (2005) with A replaced by G nucleotide in the third position in the two species of Mayetiola.

\section{- Characterization of Desmar1-like elements flanking regions by iPCR}

Analyses of fragments obtained from iPCR allowed the identification of TIRs, the dinucleotide TA as well as the flanking regions of Desmarl-like elements in M. hordei. The 5 ' and 3' sides are $231 \mathrm{bp}$ and $237 \mathrm{bp}$ in length, respectively and have a protein similarity of $53 \%$ with the helicase PIF1 5'-3 'ATP dependent in the hexapod Folsomia candida which inhibits telomere elongation by inactivation of telomerases.

\section{- Characterization of the mauritiana-like elements amplified by MauCons1 primer}

The in vitro investigation of mauritiana-like elements using the MauCons 1 primer generated four elements from $M$. destructor and five elements from $M$. hordei which were designated Mdesmar1.6 to Mdesmar1.9 and Mhormar1.8 to Mhormar1.12, respectively. These elements are available under the GenBank accession numbers MW093698 to MW093701and MW093712 to MW093716. The MauCons1-amplified elements in M. destructor sized from 1138 to $1226 \mathrm{pb}$ while those amplified in M. hordei sized from 1205 to $1214 \mathrm{bp}$.

The MauCons 1 transposases shared protein similarities ranging from $45 \%$ to $55 \%$ with Desmarl and other transposases from Drosophilidae and from the two hymenopteran species Tapinoma nigerrimum and Messor bouvieri. Moreover, the MauCons1 transposases present high similarities between elements isolated from the two species of Mayetiola as revealed by high protein similarity between Mhormar1.8, Mhormar1.9, Mhormar1.10 and Mdesmar1.7 elements ranging from $95 \%$ to $99 \%$.

Alignment of putative transposases identified in vitro and in silico showed patterns slightly different from Desmarl-like elements. The first signature motif WVPHQLL displayed an E instead of Q amino acid and the motifs flanking the transposase are modified (Figure 5). In 
addition, these transposases exhibited stop codons, and deletions spanning different signature motifs, catalytic triad as well as NLS domains. These mutations resulted in the shift of the stop codon to the 3'-TIRs in Mdesmar1.7 to Mdesmar1.9. In both species, the 5'YYAGRT3 'motif is conserved in all TIRs but with a difference at the last nucleotide which was replaced by G compared to Desmarl-like elements (Figure S1).

\section{- Characterization of the mauritiana-like elements amplified by MauCons2 primer}

Three mauritiana-like elements were amplified in M. destructor and named Mdesmar1.10 to Mdesmar1.12 (GenBank accession numbers: MW093702 to MW093704). These elements displayed total length ranging from 1229 to $1284 \mathrm{bp}$ and share $53 \%$ of protein identity with Desmar1. In M. hordei, five sequences were isolated and named Mhormar1.13 to Mhormar1.17 (GenBank accession numbers: MW093717 to MW093721). Identified elements have size varying between 1285 to $1299 \mathrm{bp}$ and share $47 \%$ of protein similarity with Desmarl.

The alignment of putative MauCons 2 transposases has shown two alignment blocks that differ by species (Figure 6). These transposases displayed WVPHQL motif and a YIG end like MauCons 1 elements. Besides, different stop codons and mutations altering the signature motifs and the DD34D triad domain were detected in all transposases.

In both species, TIRs analyses showed the modification of the 5'YYAGRT3' sequence generating the 5'YYGGRA 3 ' motif. Moreover, all TIRs are imperfect with substitution and ins/del mutations modifying the organization of the palindromic and mirror patterns (Figure S2).

Otherwise, the BLASTN performed on the TSA of $S$. mosellana using the consensus sequences generated from the three mauritiana-like elements' groups revealed four transcripts. Two partial transcripts (GAKJ01010239.1 and GAKJ01010238.1) exhibited 78\% of nucleotide similarity with Desmarl-like elements and covered only the start of transposase up to the WVPHEL signature motif. The third partial transcript (GAKJ01006734.1) exhibited a nucleotide similarity of $71 \%$ with MauCons 1 and MauCons 2 elements and spreads from the 
start of transposase to the motif WVPHQL. As for the last transcript (GBRL01006532.1), it was found to span all of the signature motifs as well as the catalytic domains with $77 \%$ of nucleotide identity (Figure 7).

\section{- Evolutionary dynamics of mauritiana-like elements}

Phylogenetic analyses of the mauritiana-like elements identified in the two Mayetiola species and $S$. mosellana by experimental and bioinformatic approaches allowed the construction of the phylogram shown in Figure 8. The branch lengths reflect the evolutionary time between sequences enabling the estimation of distances between mauritana-like elements in M. destructor, M. hordei and S. mosellana and so the estimation of the transposition events having occurred over time. The tree is divided in two major clades: the Desmar 1-like clade and the MauCons1/Maucons2 clade. Elements of Desmar1-like clade showed several subgroups with different branch lengths reflecting different events of transposition followed by accumulation of inactivating mutations in $M$. destructor. Noticeably, a burst of a recent group of Desmarl-like elements in M. destructor and M. hordei is observed. This group shares a single common ancestor with S. mosellana elements. The MauCons1/Maucons 2 clade showed a divergence of S. mosellana sequences from those of Mayetiola species. Sequences of Mayetiola split into two subclades with close branch lengths: the MauCons 1 and the MauCons 2 showing a species-related evolution.

Otherwise, all MLEs of Mayetiola and Sitodiplosis mosellana species were inferred in a phylogenetic tree to study their classification and distribution among known MLEs. The classification was performed using the UPGM-VM method from 449 nucleotide sequences. The phylogenetic analyses showed that all identified elements were clustered in a monophyletic group of mauritiana subfamily group (Figure 9).Discussion and conclusion

The mariner-like elements (MLEs) have been known to invade a big variety of arthropods and especially insects (Robertson, 1993, Yamada et al., 2015). They represent an important driver of evolution in their host genome. In the current work, we focused on the identification and characterization of MLEs belonging to the mauritiana subfamily in the two 
301

302

303

304

305

306

307

economically important pests $M$. destructor and $M$. hordei damaging respectively wheat and barley.

The combination of bioinformatic and experimental approaches allowed the identification of three mauritiana groups in the two species of Mayetiola. The first group contains elements similar to Desmarl previously reported by Russell and Shukle (1997) whereas the two other groups contain newly identified mauritiana-like elements MauCons 1 and MauCons 2 which are divergent from Desmar1. Invasions of different lineages of the same $M L E$ subfamilies have also been described in different insects including Drosophilidae (Wallau et al., 2014).

Although two MLE subfamilies were identified in M. destructor by Shukle and Russell (1995), the current study allowed the identification for the first time of MLEs belonging to mauritiana subfamily in $M$. hordei in which only irritans-like elements were reported (Ben Amara et al., 2017). Most of the Desmarl-like elements identified in $M$. destructor and $M$. hordei exhibited intact transposases displaying few mutations suggesting their recent invasions in bursts leading to the spread of several copies. This is supported by the short branches of the Desmarl-like clade in both Mayetiola species. Similar observations were reported in diatoms and vertebrates involving Tc1/mariner elements (Hermann et al., 2014, Zong et al., 2020).

The high similarity observed between the Desmarl-like sequences $(>90 \%)$ suggests a possible HT event between the two Mayetiola species. Indeed, the MLEs dynamic is often characterized by recurrent extinction followed by HT from one species to another to ensure their persistence (Lohe et al., 1995, Hartl et al., 1997a, Wallau et al., 2014). Alternatively, the high percentage of identity between Desmarl-like elements could be explained by a constant turnover of MLEs with transposition rapidly followed by loss through host purifying selection leading to a limited sequence variation (Pereira, 2004).

Transposase sequence analyses of Desmarl-like elements in M. hordei showed conserved transversion having generated a stop codon. This kind of substitutions could be a 
327

328

329

330

331

332

333

host genome mechanism to inactivate recently transposed elements by vertical inactivation (Lohe et al., 1995, Hartl et al., 1997b), given that transversions are less frequent but more detrimental than transitions (Lyons and Lauring, 2017).

Unlike M. destructor, M. hordei exhibited imperfect TIRs in Desmarl-like elements with mutations altering mirror and palindromic regions described by Bigot et al. (2005). However, this finding cannot confirm the inactivation of these elements as imperfect TIRs were previously described in naturally active MLEs like Mos1 from Drosophila mauritiana and Mboumar. 9 from Messor bouvieri. These active elements displayed different affinities for their transposase.

Otherwise, elements of MauCons1 and MauCons2 groups seem to be less active compared to Desmarl-like elements since they carry several mutations altering specific domains that lead to non-functional transposases. Such elements could be able to evolve as pseudogenes that accumulate mutations neutrally (Hartl et al., 1997b). Many other mauritiana MLEs were found to be inactive in different species like aphids (Kharrat et al., 2015) and Bruchidae species (Djebbi et al., 2017). More interestingly, some deletions were found to cover the same positions in both Mayetiola species. This could be a mechanism contributing to defective MLEs or element decay as described in the irritans subfamily (Ben Amara et al., 2017, Ben Lazhar-Ajroud et al., 2016).

Furthermore, Desmarl, MauCons1 and MauCons2-like elements exhibited high sequence identity between $M$. destructor and M. hordei which may indicate an eventual vertical inheritance of these MLEs from an intermediate common ancestor. Indeed, MLEs have been shown to undergo long-term, vertical inheritance in other dipteran genomes such as the stalk eyed flies (Carr, 2008). Similar studies carried on ants highlighted a vertical transmission with differential evolutionary success and spread into different genomes during species-separation processes (Sanllorente et al., 2020). Other studies have revealed the establishment of irritans 
352

subfamily elements in closely related Bactrocera species originating from the expansion from a common ancestor (Ben Lazhar-Ajroud et al., 2016) .

Moreover, mauritiana-like elements in Mayetiola species were found to share a common ancestor with $S$. mosellana whose sequences diverged to undergo their own evolutionary history. Indeed, in S. mosellana, the Desmarl-like elements would be counterselected since the presence of fragmented copies of MLEs while the MauCons 1/MauCons 2 elements would evolve independently from Mayetiola sequences as one clade. In the two Mayetiola species, the clade of MauCons1 and MauCons2 elements would split later in two subclades transmitted vertically to M. destructor and M. hordei. Subsequently, MauCons 1 MauCons 2 evolved in both species separately with possible HT events involving specifically MauCons1 elements. Nevertheless, an eventual introgression should not be excluded as alternative event to HT inside the MauCons 1 clade due to an old event of hybridization between M. destructor and M. hordei Similar hypothesis of introgression was recently suggested for the germline restricted chromosomes (GRCs) in the two Diptera species; Sciaridae and Cecidomyiidae (Hodson et al., 2021)

To sum up, the genomes of $M$. destructor and $M$. hordei hosted three different groups of mauritiana subfamily that have exhibited old events of transposition which occurred before the Mayetiola speciation. These groups should be inherited by vertical transmission in $M$. destructor and M. hordei genomes to undergo different evolutionary histories. According to the scenario suggested by Le Rouzic et al. (2013), the vertical transmission of mauritiana-like elements should be followed by proliferation and differentiation with accumulation of different mutations. Further studies should be focusing on the MLEs activities and insertion sites to check eventual impact on the genome evolution of these cecidomyiid flies.

\section{Conflicts of interest}

The authors declare no competing financial interests. 


\section{Acknowledgement}

382

383

The authors are grateful for the funding support of the Tunisian Ministry of Higher Education and Scientific Research.

\section{References:}

ABRUSÁN, G. \& KRAMBECK, H.-J. 2006. Competition may determine the diversity of transposable elements. Theoretical population biology, 70, 364-375.

ALTSCHUL, S. F., GISH, W., MILLER, W., MYERS, E. W. \& LIPMAN, D. J. 1990. Basic local alignment search tool. J Mol Biol, 215, 403-10.

AUGÉ-GOUILlOU, C., HAMELIN, M. H., DEMATTEI, M. V., PERIQUET, G. \& BIGOT, Y. 2001. The ITR binding domain of the Mariner Mos-1 transposase. Mol Genet Genomics, 265, 58-65.

BEHURA, S. K., SHUKLE, R. H. \& STUART, J. J. 2010. Assessment of structural variation and molecular mapping of insertion sites of Desmar-like elements in the Hessian fly genome. Insect Mol Biol, 19, 707-15.

BEN AMARA, W., DJEBBI, S., BOUKTILA, D., MAKNI, M., MAKNI, H. \& MEZGHANIKHEMAKHEM, M. 2017. An overview of irritans-mariner transposons in two Mayetiola species (Diptera: Cecidomyiidae). European Journal of Entomology, 114, 379-390.

BEN LAZHAR-AJROUD, W. C., AURORE, MEZGHANI, M., BOUALLEGUE, M., TASTARD, E., DENIS, F., ROUAULT, J.-D., MAKNI, H., CAPY, P. \& CHÉNAIS, B. 2016. Characterization of irritans mariner-like elements in the olive fruit fly Bactrocera oleae (Diptera: Tephritidae): evolutionary implications. The Science of Nature, 103, 1-14.

BIGOT, Y., BRILLET, B. \& AUGE-GOUILLOU, C. 2005. Conservation of Palindromic and Mirror Motifs within Inverted Terminal Repeats of mariner-like Elements. J Mol Biol, 351, 108-16.

BOURGEOIS, Y. \& BOISSINOT, S. 2019. On the Population Dynamics of Junk: A Review on the Population Genomics of Transposable Elements. Genes (Basel), 10.

BRILLET, B., BIGOT, Y. \& AUGE-GOUILLOU, C. 2007. Assembly of the Tc1 and mariner transposition initiation complexes depends on the origins of their transposase DNA binding domains. Genetica, 130, 105-20.

BUI, Q. T., DELAURIERE, L., CASSE, N., NICOLAS, V., LAULIER, M. \& CHENAIS, B. 2007. Molecular characterization and phylogenetic position of a new mariner-like element in the coastal crab, Pachygrapsus marmoratus. Gene, 396, 248-56.

CARR, M. 2008. Multiple subfamilies of mariner transposable elements are present in stalkeyed flies (Diptera: Diopsidae). Genetica, 132, 113-122.

CHENAIS, B., CARUSO, A., HIARD, S. \& CASSE, N. 2012. The impact of transposable elements on eukaryotic genomes: from genome size increase to genetic adaptation to stressful environments. Gene, 509, 7-15.

CHERIF, A., REZGUI, M., TITOUHI, F., YOUSSFI, S., SOLTANI, A., BARG, S., EL BOUHSSINI, M. \& MEDIOUNI BEN JEMÂA, J. 2020. Distribution, population 
dynamics and damage of Hessian fly, Mayetiola destructor (Diptera: Cecidomyiidae) in North Tunisia. Journal of Applied Entomology.

COMBET, C., BLANCHET, C., GEOURJON, C. \& DELEAGE, G. 2000. NPS@: network protein sequence analysis. Trends Biochem Sci, 25, 147-50.

DANIELS, S. B., PETERSON, K. R., STRAUSBAUGH, L. D., KIDWELL, M. G. \& CHOVNICK, A. 1990. Evidence for horizontal transmission of the P transposable element between Drosophila species. Genetics, 124, 339-355.

DJEBBI, S., BEN, A. W., MAKNI, H., MAKNI, M. \& MEZGHANI-KHEMAKHEM, M. 2017. Molecular characterization of mariner-like elements in Bruchus pisorum and Bruchus rufimanus (Coleoptera: Bruchidae). Archives of Biological Sciences, 69, $353-$ 360.

DUPEYRON, M., BARIL, T., BASS, C. \& HAYWARD, A. 2020. Phylogenetic analysis of the Tc1/mariner superfamily reveals the unexplored diversity of pogo-like elements. Mob DNA, 11, 21.

DURBIN, R. \& RICE, P. 1999. Einverted: finds DNA inverted repeats (EMBOSS). European Bioinformatics Institute, Cambridge Google Scholar.

EL BOUHSSINI, M., OGBONNAYA, F., CHEN, M., LHALOUI, S., RIHAWI, F. \& DABBOUS, A. 2013. Sources of resistance in primary synthetic hexaploid wheat (Triticum aestivum L.) to insect pests: Hessian fly, Russian wheat aphid and Sunn pest in the fertile crescent. Genetic resources and crop evolution, 60, 621-627.

EMMONS, S. W., YESNER, L., RUAN, K. S. \& KATZENBERG, D. 1983. Evidence for a transposon in Caenorhabditis elegans. Cell, 32, 55-65.

FESCHOTTE, C. \& PRITHAM, E. J. 2007. DNA transposons and the evolution of eukaryotic genomes. Annu Rev Genet, 41, 331-68.

FILEE, J., ROUAULT, J. D., HARRY, M. \& HUA-VAN, A. 2015. Mariner transposons are sailing in the genome of the blood-sucking bug Rhodnius prolixus. BMC Genomics, 16, 1061 .

FINNEGAN, D. J. 1985. Transposable elements in eukaryotes. Int Rev Cytol, 93, 281-326.

FLOR, H. H. 1971. Current status of the gene-for-gene concept. Annual review of phytopathology, 9, 275-296.

GAGNE, R. J., HATCHETT, J. H., LHALOUI, S. \& EL BOUHSSINI, M. 1991. Hessian fly and Barley stem gall midge, two different species of Mayetiola (Diptera: Cecidomyiidae) in Morocco. Annals of the Entomological Society of America, 84, 436443.

GOMULSKI, L. M., TORTI, C., BONIZZONI, M., MORALLI, D., RAIMONDI, E., CAPY, P., GASPERI, G. \& MALACRIDA, A. R. 2001. A new basal subfamily of mariner elements in Ceratitis rosa and other tephritid flies. $J$ Mol Evol, 53, 597-606.

GREEN, C. \& FROMMER, M. 2001. The genome of the Queensland fruit fly Bactrocera tryoni contains multiple representatives of the mariner family of transposable elements. Insect molecular biology, 10, 371-386.

GUIO, L. \& GONZALEZ, J. 2019. New Insights on the Evolution of Genome Content: Population Dynamics of Transposable Elements in Flies and Humans. Methods Mol Biol, 1910, 505-530.

HAMILTON, A., VOINNET, O., CHAPPELL, L. \& BAULCOMBE, D. 2002. Two classes of short interfering RNA in RNA silencing. The EMBO journal, 21, 4671-4679.

HARRIS, M. O., STUART, J. J., MOHAN, M., NAIR, S., LAMB, R. J. \& ROHFRITSCH, O. 2003. Grasses and gall midges: plant defense and insect adaptation. Annu Rev Entomol, 48, 549-77.

HARTL, D. L., LOHE, A. R. \& LOZOVSKAYA, E. R. 1997a. Modern thoughts on an ancyent marinere: function, evolution, regulation. Annu Rev Genet, 31, 337-58. 
HARTL, D. L., LOZOVSKAYA, E. R., NURMINSKY, D. I. \& LOHE, A. R. 1997b. What restricts the activity of mariner-like transposable elements? Trends in Genetics, 13, 197201.

HASEGAWA, M., KISHINO, H. \& YANO, T. 1985. Dating of the human-ape splitting by a molecular clock of mitochondrial DNA. J Mol Evol, 22, 160-74.

HATCHETT, J. \& GALLUN, R. L. 1970. Genetics of the ability of the Hessian fly, Mayetiola destructor, to survive on wheats having different genes for resistance. Annals of the Entomological Society of America, 63, 1400-1407.

HERMANN, D., EGUE, F., TASTARD, E., NGUYEN, D.-H., CASSE, N., CARUSO, A., HIARD, S., MARCHAND, J., CHÉNAIS, B. \& MORANT-MANCEAU, A. 2014. An introduction to the vast world of transposable elements-what about the diatoms? Diatom Research, 29, 91-104.

HODSON, C. N., JARON, K. S., GERBI, S. A. \& ROSS, L. 2021. Evolution of gene-rich germline restricted chromosomes in black-winged fungus gnats through introgression (Diptera: Sciaridae). bioRxiv.

JACOBSON, J. W., MEDHORA, M. M. \& HARTL, D. L. 1986. Molecular structure of a somatically unstable transposable element in Drosophila. Proc Natl Acad Sci U S A, 83, 8684-8.

KAPITONOV, V. V. \& JURKA, J. 2008. A universal classification of eukaryotic transposable elements implemented in Repbase. Nat Rev Genet, 9, 411-2; author reply 414.

KHARRAT, I., MEZGHANI, M., CASSE, N., DENIS, F., CARUSO, A., MAKNI, H., CAPY, P., ROUAULT, J. D., CHENAIS, B. \& MAKNI, M. 2015. Characterization of marinerlike transposons of the mauritiana Subfamily in seven tree aphid species. Genetica, 143, 63-72.

KIDWELL, M. G. \& LISCH, D. 1997. Transposable elements as sources of variation in animals and plants. Proc Natl Acad Sci US A, 94, 7704-11.

KIDWELL, M. G. \& LISCH, D. R. 2001. Perspective: transposable elements, parasitic DNA, and genome evolution. Evolution, 55, 1-24.

KLAI, K., CHÉNAIS, B., ZIDI, M., DJEBBI, S., CARUSO, A., DENIS, F., CONFAIS, J., BADAWI, M., CASSE, N. \& MEZGHANI KHEMAKHEM, M. 2020. Screening of Helicoverpa armigera Mobilome Revealed Transposable Element Insertions in Insecticide Resistance Genes. Insects, 11, 879.

KUMAR, S., STECHER, G., LI, M., KNYAZ, C. \& TAMURA, K. 2018. MEGA X: Molecular Evolutionary Genetics Analysis across Computing Platforms. Mol Biol Evol, 35, 15471549.

LAMPE, D. J., WITHERSPOON, D. J., SOTO-ADAMES, F. N. \& ROBERTSON, H. M. 2003. Recent horizontal transfer of mellifera subfamily mariner transposons into insect lineages representing four different orders shows that selection acts only during horizontal transfer. Mol Biol Evol, 20, 554-62.

LE ROUZIC, A. \& CAPY, P. 2005. The first steps of transposable elements invasion: parasitic strategy vs. genetic drift. Genetics, 169, 1033-43.

LE ROUZIC, A., PAYEN, T. \& HUA-VAN, A. 2013. Reconstructing the evolutionary history of transposable elements. Genome Biol Evol, 5, 77-86.

LETUNIC, I. \& BORK, P. 2016. Interactive tree of life (iTOL) v3: an online tool for the display and annotation of phylogenetic and other trees. Nucleic Acids Res, 44, W242-5.

LIN, J. R. \& HU, J. 2013. SeqNLS: nuclear localization signal prediction based on frequent pattern mining and linear motif scoring. PLoS One, 8, e76864.

LOHE, A. R. \& HARTL, D. L. 1996. Autoregulation of mariner transposase activity by overproduction and dominant-negative complementation. Mol Biol Evol, 13, 549-55.

LOHE, A. R., MORIYAMA, E. N., LIDHOLM, D. A. \& HARTL, D. L. 1995. Horizontal transmission, vertical inactivation, and stochastic loss of mariner-like transposable elements. Mol Biol Evol, 12, 62-72. 
LONG, H., LI, M. \& FU, H. 2016. Determination of optimal parameters of MAFFT program based on BAliBASE3.0 database. Springerplus, 5, 736.

LYONS, D. M. \& LAURING, A. S. 2017. Evidence for the Selective Basis of Transition-toTransversion Substitution Bias in Two RNA Viruses. Mol Biol Evol, 34, 3205-3215.

MACKAY, T. F. 1989. Transposable elements and fitness in Drosophila melanogaster. Genome, 31, 284-95.

MEZGHANI KHEMAKHEM, M., MAKNI, H. \& MARRAKCHI, M. Identification par PCRRFLP de marqueurs mitochondriaux chez deux espèces de Mayetiola nuisibles aux cultures de céréales (Diptera: Cecidomyiidae). Annales de la Société entomologique de France, 2002. 277-282.

NICHOLAS, K. B. \& NICHOLAS, H. B. J. 1997. GeneDoc: a tool for editing and annotating multiple sequence alignments. Distributed by the author. 1997.

OLIVEIRA, S. G., BAO, W., MARTINS, C. \& JURKA, J. 2012. Horizontal transfers of Mariner transposons between mammals and insects. Mobile Dna, 3, 1-6.

PEREIRA, V. 2004. Insertion bias and purifying selection of retrotransposons in the Arabidopsis thaliana genome. Genome Biol, 5, R79.

PIRIYAPONGSA, J. \& JORDAN, I. K. 2007. A family of human microRNA genes from miniature inverted-repeat transposable elements. PLoS One, 2, e203.

PLASTERK, R. H., IZSVAK, Z. \& IVICS, Z. 1999. Resident aliens: the Tc1/mariner superfamily of transposable elements. Trends Genet, 15, 326-32.

PLASTERK, R. H. \& VAN LUENEN, H. G. 2002. The Tc1/mariner family of transposable elements. Mobile DNA II. American Society of Microbiology.

RATClifFE, R. H., CAMBRON, S. E., FLANDERS, K. L., BOSQUE-PEREZ, N. A., CLEMENT, S. L. \& OHM, H. W. 2000. Biotype composition of Hessian fly (Diptera: Cecidomyiidae) populations from the southeastern, midwestern, and northwestern United States and virulence to resistance genes in wheat. Journal of Economic Entomology, 93, 1319-1328.

ROBERTSON, H. M. 1993. The mariner transposable element is widespread in insects. Nature, $362,241-245$.

ROBERTSON, H. M. 1997. Multiple Mariner transposons in flatworms and hydras are related to those of insects. $J$ Hered, 88, 195-201.

ROBERTSON, H. M. \& ASPLUND, M. L. 1996. Bmmar1: a basal lineage of the mariner family of transposable elements in the silkworm moth, Bombyx mori. Insect Biochem Mol Biol, 26, 945-54.

ROBERTSON, H. M. \& LAMPE, D. J. 1995. Recent horizontal transfer of a mariner transposable element among and between Diptera and Neuroptera. Molecular Biology and Evolution, 12, 850-862.

ROBERTSON, H. M. \& MACLEOD, E. G. 1993. Five major subfamilies of mariner transposable elements in insects, including the Mediterranean fruit fly, and related arthropods. Insect Mol Biol, 2, 125-39.

ROBERTSON, H. M., SOTO-ADAMES, F. N., WALDEN, K. K., AVANCINI, R. M. \& LAMPE, D. J. 2002. The mariner transposons of animals: horizontally jumping genes. Horizontal gene transfer. Elsevier.

ROUAULT, J.-D., CASSE, N., CHÉNAIS, B., HUA-VAN, A., FILÉE, J. \& CAPY, P. 2009. Automatic classification within families of transposable elements: application to the mariner Family. Gene, 448, 227-232.

RUSSELL, V. W. \& SHUKLE, R. H. 1997. Molecular and cytological analysis of a mariner transposon from Hessian fly. J Hered, 88, 72-6.

SANG, Y., GAO, B., DIABY, M., ZONG, W., CHEN, C., SHEN, D., WANG, S., WANG, Y., IVICS, Z. \& SONG, C. 2019. Incomer, a DD36E family of Tc1/mariner transposons newly discovered in animals. Mob DNA, 10, 45. 
SANLlORENTE, O., VELA, J., MORA, P., RUIZ-MENA, A., TORRES, M. I., LORITE, P. \& PALOMEQUE, T. 2020. Complex Evolutionary History of Mboumar, a Mariner Element Widely Represented in Ant Genomes. Sci Rep, 10, 2610.

SHAO, H. \& TU, Z. 2001. Expanding the diversity of the IS630-Tc1-mariner superfamily: discovery of a unique DD37E transposon and reclassification of the DD37D and DD39D transposons. Genetics, 159, 1103-15.

SHUKLE, R. H. \& RUSSELL, V. W. 1995. Mariner transposase-like sequences from the Hessian fly, Mayetiola destructor. $J$ Hered, 86, 364-8.

STUART, J. J., CHEN, M. S., SHUKLE, R. \& HARRIS, M. O. 2012. Gall midges (Hessian flies) as plant pathogens. Annu Rev Phytopathol, 50, 339-57.

SUNNUCKS, P. \& HALES, D. F. 1996. Numerous transposed sequences of mitochondrial cytochrome oxidase I-II in aphids of the genus Sitobion (Hemiptera: Aphididae). Mol Biol Evol, 13, 510-24.

TOUCHON, M. \& ROCHA, E. P. 2007. Causes of insertion sequences abundance in prokaryotic genomes. Mol Biol Evol, 24, 969-81.

WALLAU, G. L., CAPY, P., LORETO, E. \& HUA-VAN, A. 2014. Genomic landscape and evolutionary dynamics of mariner transposable elements within the Drosophila genus. BMC Genomics, 15, 727.

WANG, S., DIABY, M., PUZAKOV, M., ULLAH, N., WANG, Y., DANLEY, P., CHEN, C., WANG, X., GAO, B. \& SONG, C. 2021. Divergent evolution profiles of DD37D and DD39D families of Tc1/mariner transposons in eukaryotes. Mol Phylogenet Evol, 161, 107143.

WICKER, T., SABOT, F., HUA-VAN, A., BENNETZEN, J. L., CAPY, P., CHALHOUB, B., FLAVELL, A., LEROY, P., MORGANTE, M., PANAUD, O., PAUX, E., SANMIGUEL, P. \& SCHULMAN, A. H. 2007. A unified classification system for eukaryotic transposable elements. Nat Rev Genet, 8, 973-82.

XIE, Z., JOHANSEN, L. K., GUSTAFSON, A. M., KASSCHAU, K. D., LELLIS, A. D., ZILBERMAN, D., JACOBSEN, S. E. \& CARRINGTON, J. C. 2004. Genetic and functional diversification of small RNA pathways in plants. PLoS Biol, 2, E104.

YAMADA, K., YAMADA, A., KAWANISHI, Y., GURUNG, R. D., SASAKI, T., TOKUDA, G. \& MAEKAWA, H. 2015. Widespread distribution and evolutionary patterns of mariner-like elements among various spiders and insects. Journal of Insect Biotechnology and Sericology, 84, 2_029-2_041.

YUAN, Y.-W. \& WESSLER, S. R. 2011. The catalytic domain of all eukaryotic cut-and-paste transposase superfamilies. Proceedings of the National Academy of Sciences, 108, 7884-7889.

ZHANG, H. H., LI, G. Y., XIONG, X. M., HAN, M. J., ZHANG, X. G. \& DAI, F. Y. 2016. TRT, a Vertebrate and Protozoan Tcl-Like Transposon: Current Activity and Horizontal Transfer. Genome Biol Evol, 8, 2994-3005.

ZHANG, Y., GROSSE-HONEBRINK, A. \& MINTON, N. P. 2015. A universal mariner transposon system for forward genetic studies in the genus Clostridium. PLoS One, 10, e0122411.

ZONG, W., GAO, B., DIABY, M., SHEN, D., WANG, S., WANG, Y., SANG, Y., CHEN, C., WANG, X. \& SONG, C. 2020. Traveler, a New DD35E Family of Tc1/Mariner Transposons, Invaded Vertebrates Very Recently. Genome Biol Evol, 12, 66-76. 
624

625

626

627

628 
a.

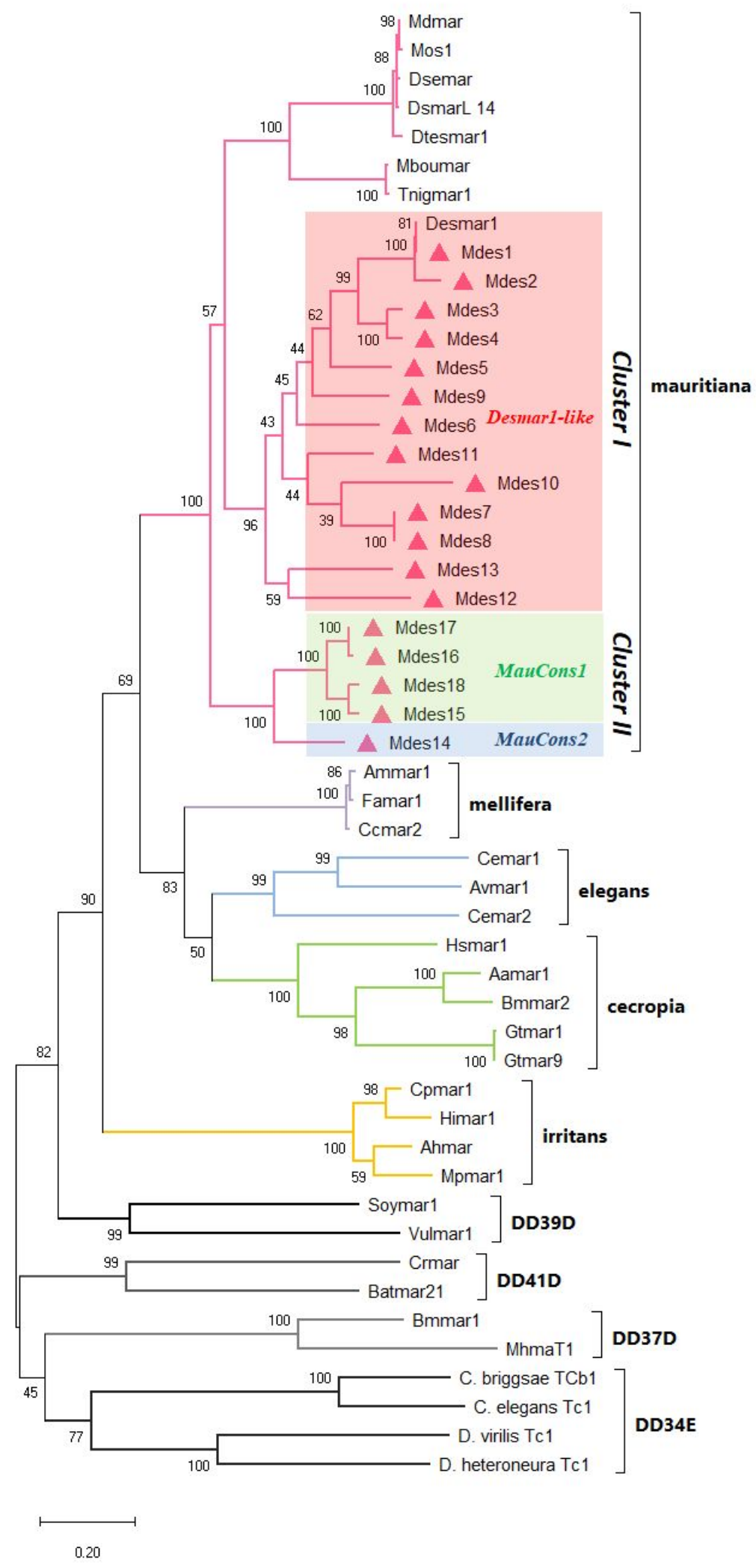


b.
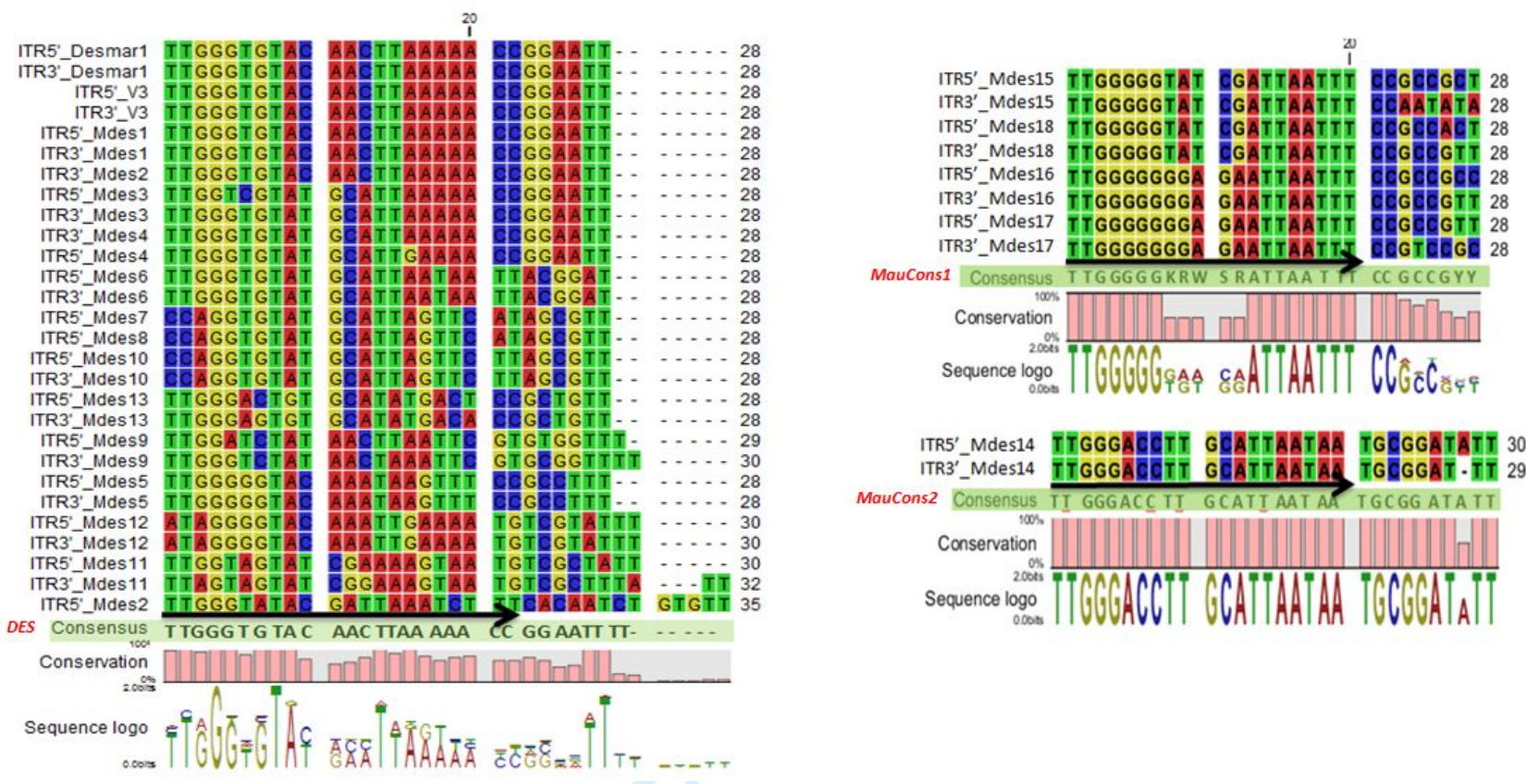

Figure 1. a. Phylogeny based on the nucleotide sequences of the 18 full length mauritiana-like elements

identified in silico in $M$. destructor b. Representation of the primers designated from the ends of the TIRs of the three consensus DES, MauCons1 and MauCons2

The tree was inferred using the Maximum Likelihood method (model HKY85) with a bootstrap of 1000 replications. The bootstrap values for nodes below 50\% were omitted. The reference elements belonging to the 5 sub-families of MLEs, the TLEs (DD34E), the maT (DD37D), the Plant MLE (DD39D) and the rosa elements (DD41D) were taken from the GenBank database and whose accession numbers are as follows: M. destructor Desmar1 (U24436.1) DIv3-Hf (DQ015886.1), Tapinoma nigerrimum Tnigmar (HE577149.1), Messor bouvieri Mboumar (AJ781770.1), Drosophila teissieri Dtesmar1 (AF035567.1), Drosophila simulans DsmarL14 (AF037055.1), Drosophila sechellia Dsemar (AF035569.1), D.mauritiana Mos1 (M14653.1), Musca domestica Mdmar1 (AF373028.1), Ceratitis capitata Ccmar2 (AY155493.1), Apis mellifera Ammar1 (AY155490.1), Forficula auricularia Famar1 (AY155492.1), Girardia tigrina Gtmar1 (X71979.1), Gtmar9 (X80894.1), Attacus atlas Aamar1 (AB006464.1), Bombyx mori Bmmar2 (D88671.1), Haematobia irritans Himar1 (U11642.1), H. sapiens Hsmar2 (U49974.1), Chrysoperla plorabunda Cpmar1 (U11654.1), Mantispa pulchella Mpmar1 (U11649.1), Adoxophyes honmai Ahmarl (AB020617.1), Caenorhabditis elegans Cemar1(AF014939_1), Cemar2 (Y39A3A_1), Adineta vaga Avmar1 (DQ138284_1), Glycine max Soymar1 (AF078934.1), Beta vulgaris 
Vulmarl (AJ556159.1), Ceratitis rosa Crmarl (AY034623.1), Bactrocera tryoni Batmar2 (KX931016.1), Bombyx mori Bmmarl (U47917.1), Misgolas hubbardi MhmaT1 (JF779677.1), Caenorhabditis briggsae TCb1 (X54218.1), Caenorhabditis elegans Tc1 (X01005.1), Drosophila virilis Tc1-like (U26938.1), Drosophila heteroneura Tc1( X17356.1). 


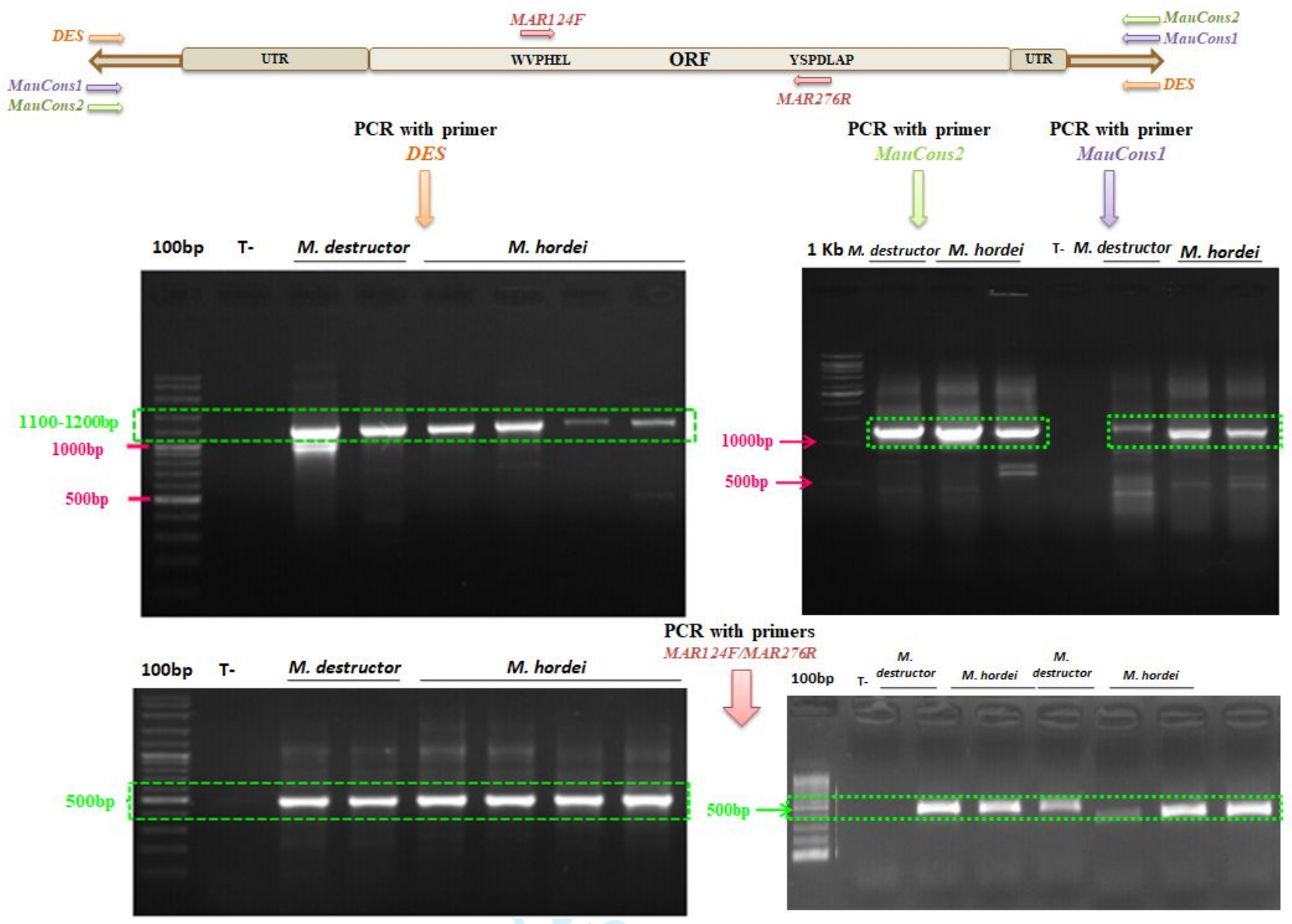

Figure 2. Results of PCR amplifications of the mauritiana-like elements in M. destructor and M. hordei obtained by the DES, MauCons1, MauCons 2 and the internal primers

$100 \mathrm{bp}$ and $1 \mathrm{~kb}$ denote size markers (Ladder) 

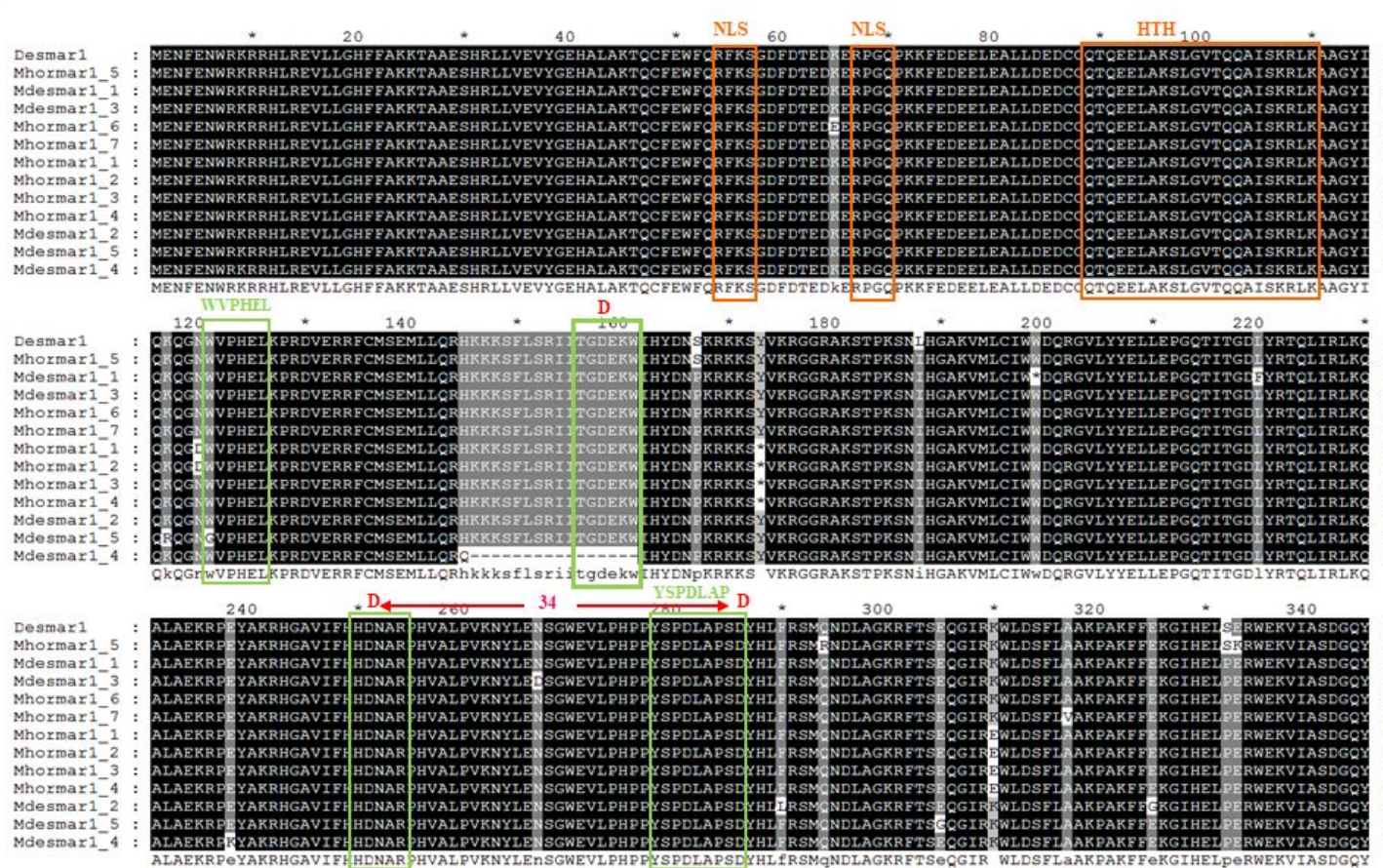

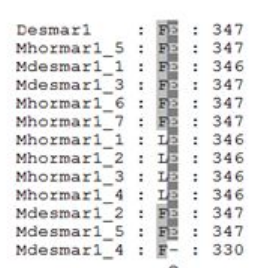

b.

Desmar1_5' TIR Desmar1_ $3^{\prime}$ TIR

2)

"TIGGTGTCAACTTAAAACCGGATT YYGGRT

Mdesmar1 $\mathrm{S}^{\prime} \mathrm{TIR}$

ㄴ.

"YYGGRT

Mhormar1_5' TIR

2

TIGGTGTACACTTAAAALCCGAAT ${ }^{5}$ YYGGRT

Mdesmar1 $3^{\prime}$ TIR

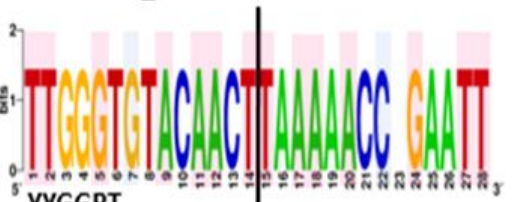
YYGGRT Mhormar1_3' TIR

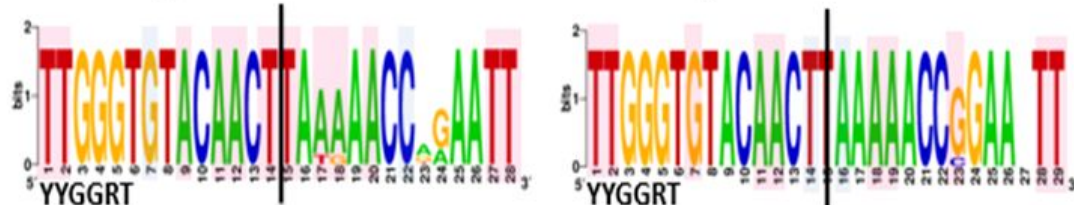

Figure 3. Characterization of Desmar 1-like elements identified by PCR-based method in M. destructor and M. hordei

a. alignment of the putative transposases resulting from the in silico translation of the 12 mauritiana-like elements identified in the two Mayetiola species b. logos of the 5 'and 3 ' TIRs consensus of the Mdesmarl and Mhormarl elements: palindromic patterns are marked in blue and mirror patterns are marked in pink. 

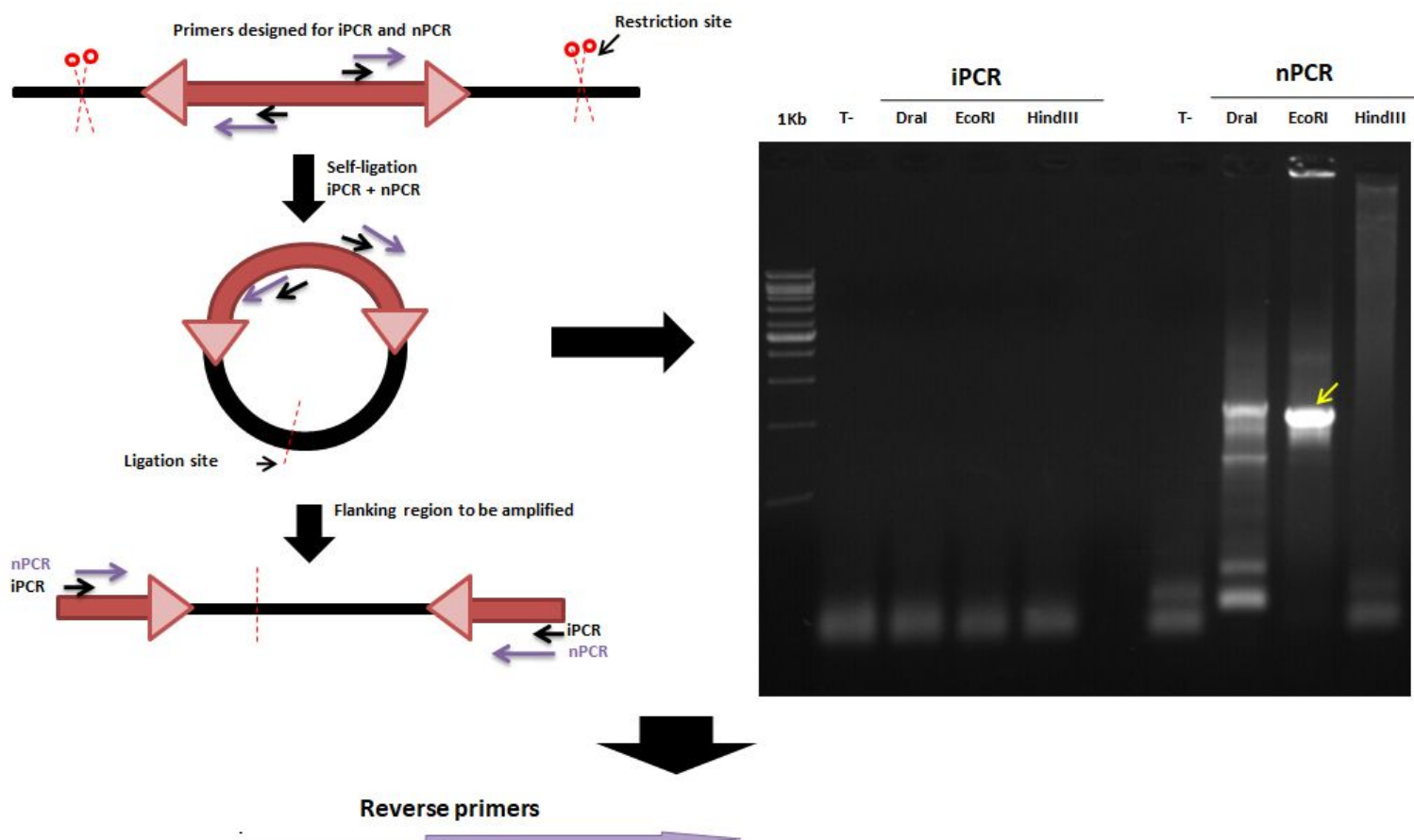

GTCTTCCGTATCAAAGTCACCACTITG AAGCGTTGAAACCATTCGAAACACTGTGTITTGCTAAGGCATGTTC GCCGTAAACTTCCACAAGCAAACGGTGACTTCTGCAGCAGTIIIITGCAAAAAAGTGGCCCAACAAAACT CCCGCAAATGCCGTCTITTCGCCAG TITTCAAAATTTTCCATAGTTAATAAAAAAATATGATGCACACAGATAG AATAG TITATTGACTGATITGATAGCTGTCAAATGTACCTTCAAAATGACGTATATATGAAATTGTGCTIT ACACTATTG TTAGTGTG GACATCTAGCGTCCAATTCCGGTIITAAGTTGTACACCCAATACCTCGAAATTIA AATGACACACATACAATACAAATTCATTTAAGACGTAAAATGAGTAACAAACACGACTATATGCACGGAACAA TCAGACCAGCAAAAATITGGAAGCTGCAAACTATITAGTTACGACTCCAGTTATAAAAAGGAAAACATTCAT ATTTCTAATTCATGGAAAGAG GACAACAACTTAGATGTAAATCCAGAAGAACATCAACCGCTCATTACCTCTGA ATTCTGTAAACATGCTATGATAACATAAATGCAGGGAAAATACCAAATTATGTTTAACAAATGGACTGGGATT CAAAAAAATTCCAGATTTCTTGAAAGACCTTACTATCGACGAAGAACGCTTAATATCACCTCGAATCCCTITTAT GAGAATAAGAAAATTGGGATATGAACATCAATATGGTATGAAAGGAGCTGTCGTAAACGTTCCAGTATCAATA GATAAAATCATTAGAGTACTATTGGGTGACAACTIAAAAACCGGAATITTAGTGAAAATTAATGCTTATT TCGATAACAAAATGAATGAATGCATTATTCAAAGTATTGCCCATCTGAAGCTATGACTITTCCCATCTITCTGG CAATTCATGGATTCCCTTCTCAAACAACTTCGCCGGCTTGGCGGCCAAGAATGAATCAAGCCATTTCGGATAC CCTGCTCTGAAGTGAAGCGTITIC

Forward primers

Figure 4.iPCR and nPCR results for regions flanking $M L E$ obtained from $M$. hordei

The yellow arrow on the gel indicates the excised band. In the sequence obtained, the underlined region corresponds to the DNA flanking the element Mhormarl; the region in grey is the one surrounding the 5' side of the element and amplified by the reverse primers while the underlined black region corresponds to the one surrounding the 3' side of the element and amplified by the sense primers. The black primers correspond to iPCR and the primers in purple correspond to nPCR. The EcoRI enzyme restriction site is marked in blue. Element TIRs are boxed and bordered by TA dinucleotide (TSD) and $M L E$ sequences are marked in burgundy red. 

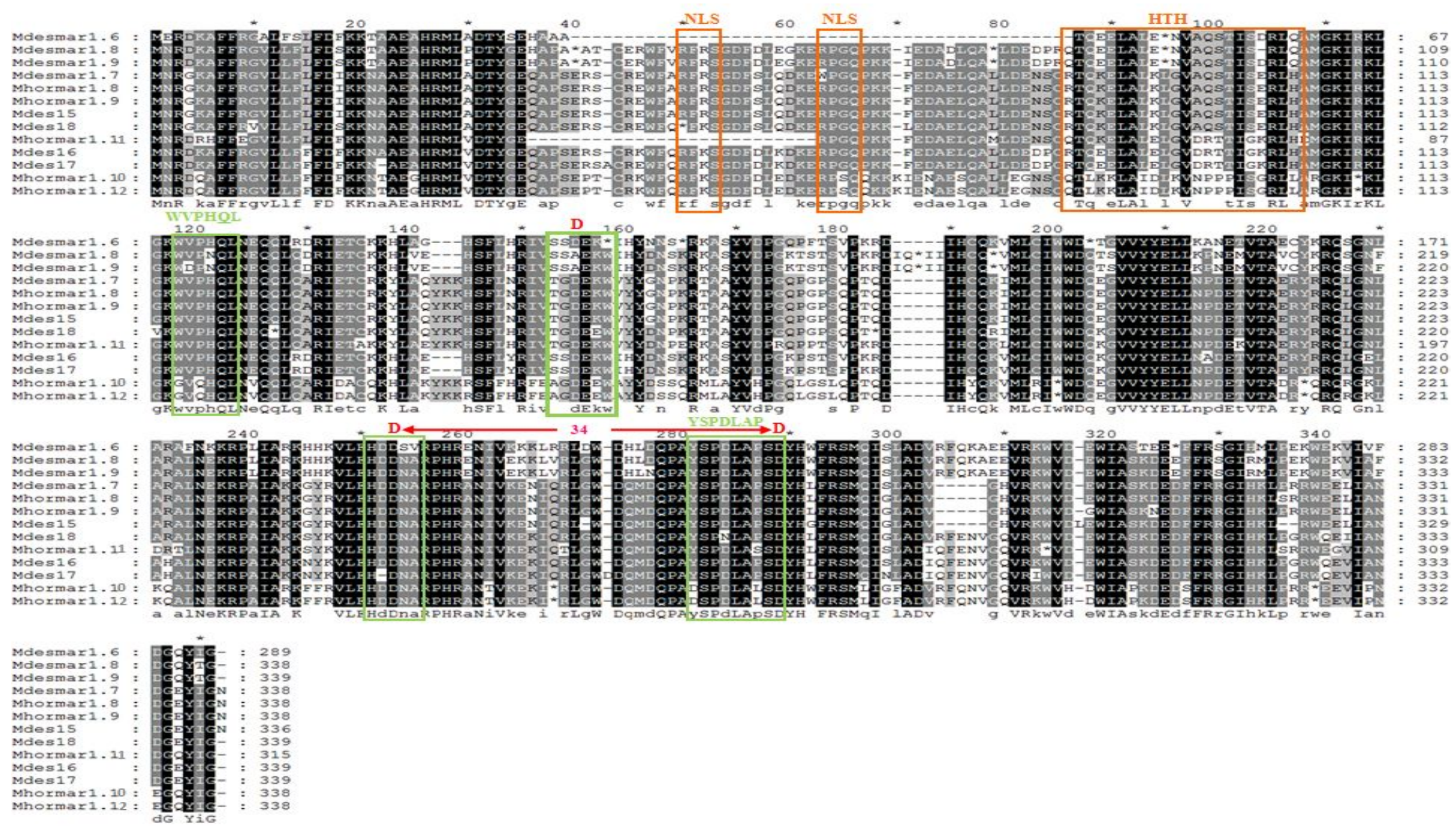

Figure 5. Alignment of putative transposases of mauritiana-like elements amplified by MauCons 1 primer in M. destructor and M. hordei 


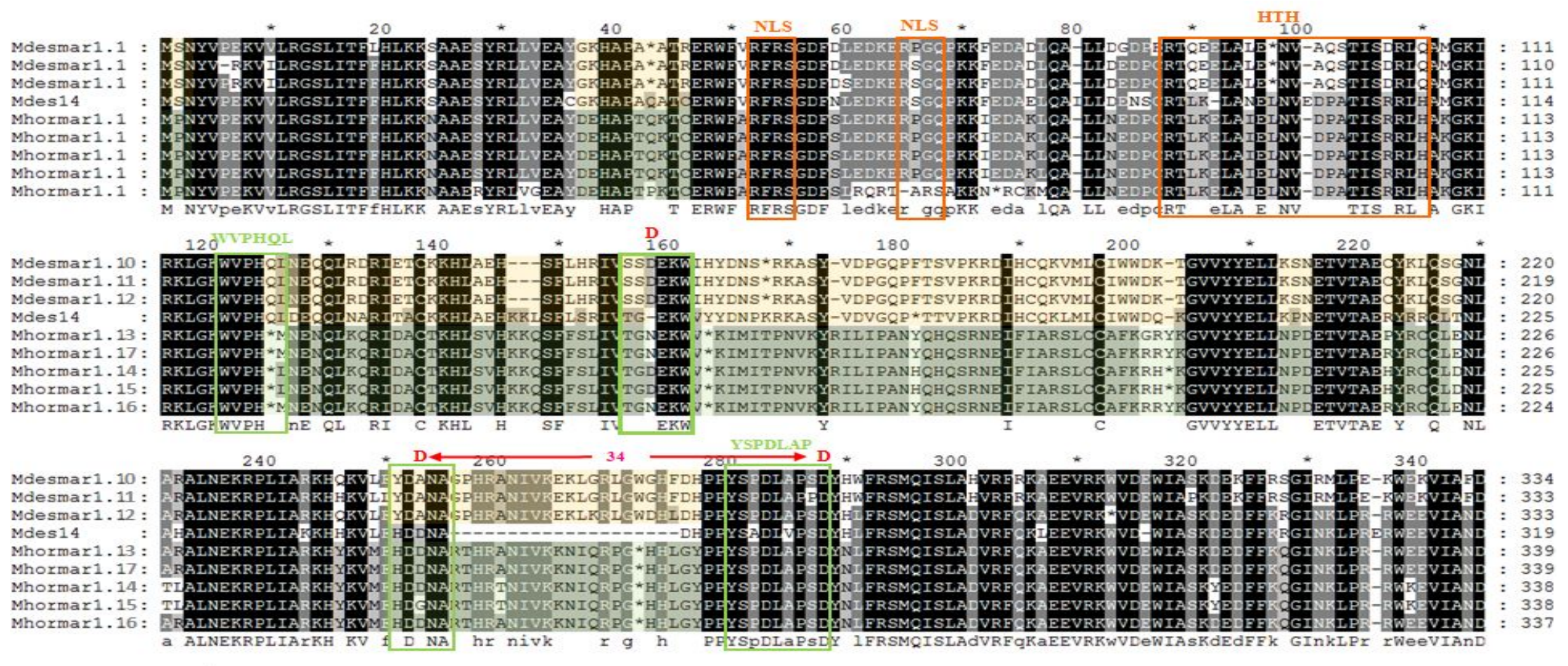

Mdesmar1.10: GQYI :
Mdesmar1.11: GQYIG $: 339$
Mdesmar1.12: GQYIG $: 338$
Mdes14 : GQYIG $: 324$
Mhormar1.13: GQYIG $: 344$
Mhormar1.17: GQYIG $: 344$
Mhormar1.14: GQYIG $: 343$
Mhormar1.15: GQYIG : 343
Mhormar1.16: GQYIG : 342

Figure 6. Alignment of putative transposases of mauritiana-like elements amplified by MauCons 2 primer in M. destructor and M. hordei 


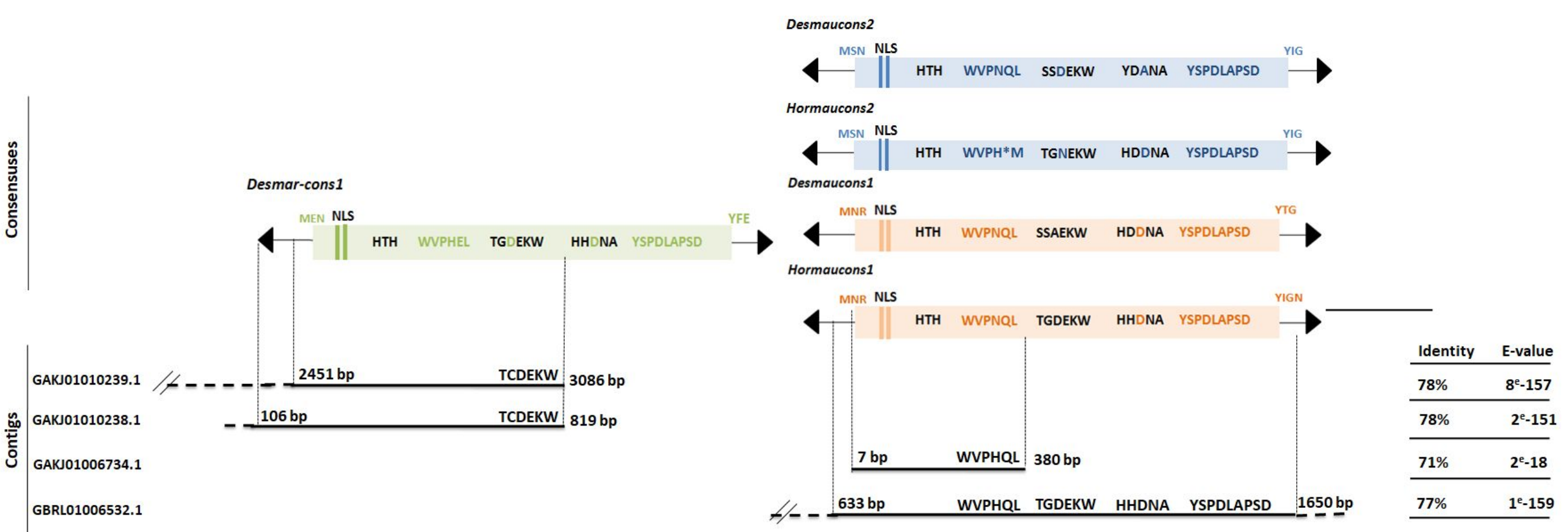

Figure 7. Comparison between the cDNA contigs identified in S. mosellana and MLE consensus constructed from the mauritiana-like elements of M. destructor (Desmar-cons1, Desmaucons1 and Desmaucons2) and M. hordei (Hormaucons1 and Hormaucons2) 


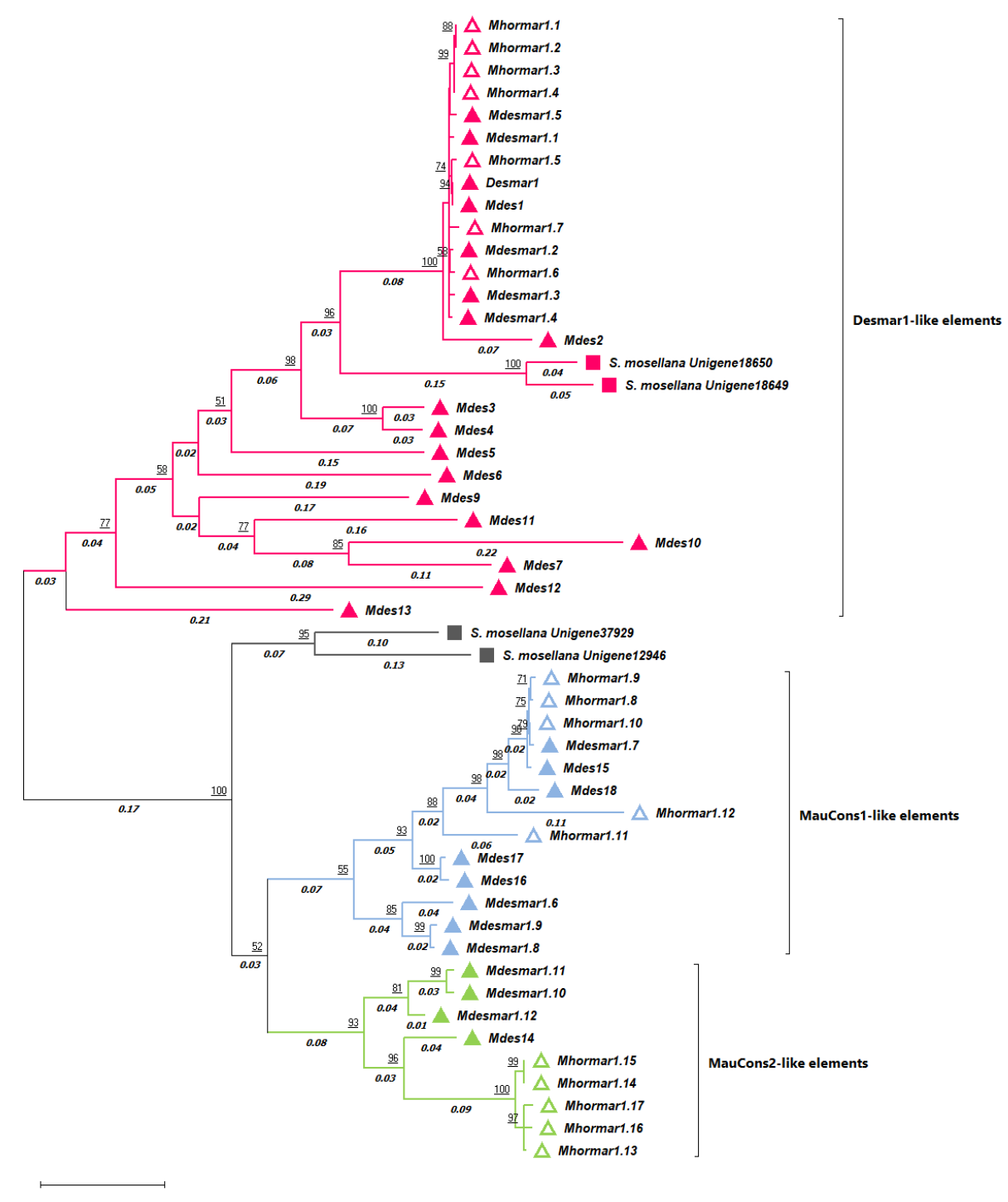

Figure 8. Phylogram of identified mauritiana-like elements in the two Mayetiola species and in Sitodiplosis mosellana. 
- MLEs of mellifera subfamily

- MLEs of mauritiana subfamily (including Mhormarl and Mdesmarl MLEs)

- Mhormar1 MLE

- Mdesmar1 MLEs

- MLEs of capitata subfamily

- MLEs of human irritans subfamily

_ MLEs of cecropia subfamily

- MLEs of elegans/briggsae subfamily

_ MLEs of arthropod irritans subfamily

— Other MLE subfamilies, TLEand IS external groups

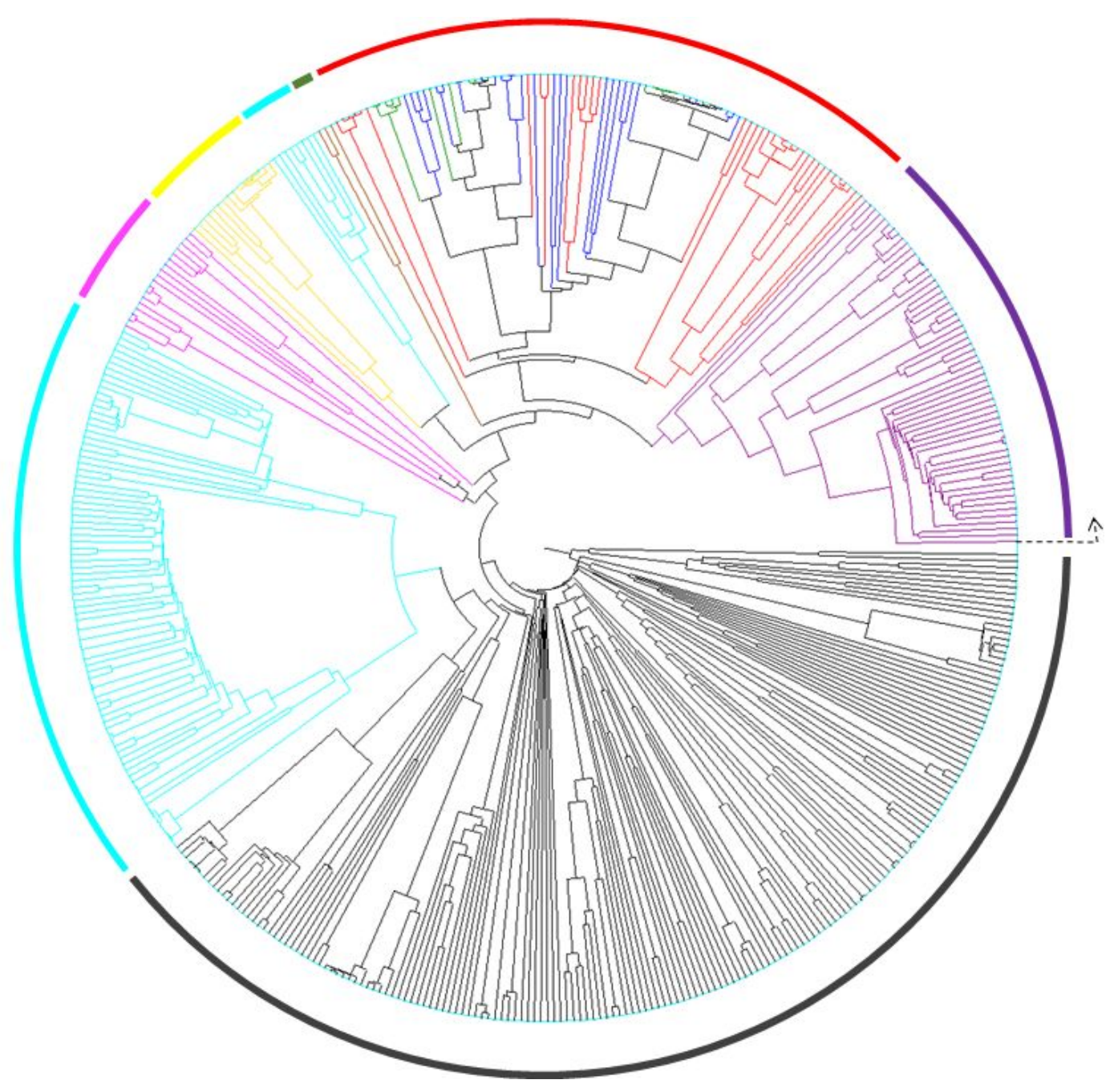

Figure 9. Classification of Mhormarl and Mdesmar1 MLEs using the UPGM-VM method among a set of 449 transposable elements beloning to the Tc1/mariner superfamily. The 449 elements were subdivised in 8 groups: MLEs of mellifera subfamily (59 sequences), MLEs of mauritiana subfamily ( 87 sequences including 31 Mdesmarl elements, 18 Mhormar1 elements and 4 S. mosellanae elements), MLE of capitata subfamily (3 sequences), MLE of human irritans subfamily (8 sequences), MLE of cecropia subfamily (15 sequences), MLEs of briggsaelelegans subfamily (18 sequences), MLE of arthropod irritans subfamily (136 
sequences) and the external group containing 124 other MLEs, TLEs and IS elements indicated with black branches. The reading sense of this circular tree is indicated at right by a dashed arrow 